\title{
Relationship of Waist-Hip Ratio and Body Mass Index to Blood Pressure of Individuals in Ibadan North Local Government
}

\author{
Sanya, A.O., Ogwumike, O.O., Ige A.P., Ayanniyi, O.A. \\ Department of Physiotherapy, College of Medicine, University of Ibadan \\ Correspondence \\ O.O. Ogwumike, Department of Physiotherapy, College of Medicine, University of Ibadan
}

\begin{abstract}
SUMMARY
Several studies have shown that there is a significant relationship between relative weight and hypertension. The anatomical distribution of weight has also been shown to be a factor in determining which people are more susceptible to hypertension and thus at risk of developing cardiovascular diseases.

This study investigated the relationship between two anthropometric measurements for obesity - body mass index (BMI) and waist-hip ratio (WHR), and the blood pressure of Nigerians aged 15-85 years. The study employed a cross-sectional survey of individuals living in Ibadan North Local Government Area of Oyo State. Four hundred and four male and female individuals were recruited using a non-probability sampling technique. Measurements taken include subjects' systolic and diastolic blood pressure, waist and hip girths, height, and weight. Information was obtained about lifestyle and occupation as well as familial history of hypertension, diabetes, cardiac and renal diseases.

Data was analysed using descriptive and inferential statistics, with alpha set at 0.05 . Results show that WHR and BMI had a linear relationship with the blood pressure of the participants.
\end{abstract}

KEY WORDS: blood pressure, body mass index, waist-hip ratio, hypertension

\section{INTRODUCTION}

The relationship between excess weight and diseases has been recognized over time (Visscher and Seidell, 2001; Cameron et al, 2003). Obesity has been particularly recognized as a major independent risk factor for cardiovascular diseases (Despres, 2001). This is because increased body fat is accompanied by profound changes in the physiological and metabolic functions of the body, which are directly dependent on the degree of excess weight and on its distribution around the body.

The prevalence of obesity is rising in developed and developing nations, and it is cited as an important risk factor for early mortality (WHO, 1998). Obesity has a strong relationship with cardiovascular diseases like hypertension (Stevens et al, 1998; Despres, 2001; Cameron et al, 2003), coronary heart disease and diabetes. A number of clinical measurements for obesity have been used to determine susceptibility to cardiovascular diseases (Cameron et al, 2003). These include anthropometric indices such as body mass index (BMI), waist-hip ratio (WHR) and waist circumference (WC) (Bray and Gray, 1988; Flier and Flier, 2005).
Body mass index has been identified by the World Health Organization as the most useful epidemiological measure of obesity. It is nevertheless a crude index that does not take into account the distribution of body fat, resulting in variability in different individuals and populations (WHO, 2000). In the assessment of obesity, the central distribution of body fat cannot be overlooked, hence, the use of other anthropometric indices such as WC and WHR, as measures of adiposity (Welborn et al, 2003). Waist circumference has been recommended as a simple and practical measure for identifying overweight and obese patients. It is particularly useful for individuals and population groups with different body builds (Larson et al, 1984; Lapidus et al, 1984; Welborn et al, 2003).

In this study, BMI and WHR were used to assess body fat distribution. BMI is more accurate in assessing excess weight than the measurement of weight alone, due to its accessibility and reproducibility (WHO, 2000). BMI is computed by dividing weight (in kilograms) by square height (in metres). Waist-hip ratio has been shown to be a better and simpler indicator of both intra-abdominal fat (Lemieux et al, 1996) and coronary artery disease, than 
BMI (Ohlson et al, 1985). It is less dependent on body size and height (Welborn et al, 2003), but more on hip circumference, which is an index of muscle mass (James, 1996). Waist-to-hip girth ratio is computed as abdominal girth (in centimetres) divided by hip girth (in centimetres), where waist girth represents the smallest girth around the abdomen (natural waist) and hip girth reflects the largest girth measured around the buttocks (McArdle et al, 2000).

Cardiovascular diseases (CVDs) are one of the leading causes of death in both men and women in most Western countries (Padwal et al, 2001). From ages 35-60 years, the systolic and diastolic blood pressure increases at an average of $20 / 10 \mathrm{~mm} \mathrm{Hg}$, however, the systolic blood pressure is the most consistent and significant risk factor for CVDs compared to the diastolic blood pressure (Neaton and Wentworth, 1992).

Several studies showing the relationship of WHR, BMI and blood pressure to cardiovascular diseases have been carried out on Caucasians (Lapidus et al, 1984; Larson et al, 1984; Prineas et al, 1993). However, there is a dearth of literature on this type of study on Africans, particularly in Nigeria. This study was therefore designed to investigate the relationship of WHR and BMI to blood pressure in individuals aged 15-85 years in a Nigerian population.

\section{MATERIALS AND METHODS}

\section{Participants}

The participants in this study were from designated centres within Ibadan North Local Government Area of Oyo State. They were from Abadina College, University of Ibadan; Methodist Grammar School, Bodija; Alexander Brown Hall, University of Ibadan; as well as from primary health care centres in Agbowo, Barika and Kara in Ibadan. Selection was by a sample of convenience based on the cooperation of the principals of the schools, the management of the primary health care centres as well as readiness of the participants after their informed consent. Male and female participants who met the inclusion criteria for the study were selected using a non-probability sampling technique.

\section{Instrumentation}

1. Inelastic tape measure (Butterfly model - made in China), graduated in centimetres (0-150) was used to measure the waist and hip circumferences.

2. Height metre: A vertical wooden bar calibrated in centimetres (0-200) with a movable horizontal bar which could be adjusted to touch the vertex of the participant's head was used to measure the height of the participants.

3. Sphygmomanometer: A mercury-in-glass sphygmomanometer calibrated in millimetres of mercury from 0 - $300 \mathrm{mmHg}$ was used to measure the blood pressure of participants to the nearest 1 millimetre of mercury with the aid of a Littman stethoscope (USA).

4. A portable bathroom weighing scale (Camry) calibrated from $0-120 \mathrm{~kg}$ was used to measure body weight to the nearest kilogram.

Prior to the commencement of the study, ethical approval was obtained from the University of Ibadan/University College of Medicine Institutional Review Board. The rationale behind the study, including the procedure was explained to the participants. The participants' weight and height were measured and used to calculate the BMI. The waist circumference was measured with a tape measure to within 1 millimetre midway between the lowest rib and the iliac crest, with the participant in the upright position (WHO,1998). This was done twice and the average of the two measurements taken as WC. Hip circumference was measured, with the participant standing erect, feet together and on a horizontal plane at the level of the greater trochanters. This was also done twice and the average measurement taken as HC (McArdle et al, 2000). The waist-hip-ratio was calculated by dividing the waist circumference by the hip circumference. Blood pressure measurement by the auscultatory method was done after 5 minutes of allowing the participant to remain in the sitting position. Participants with systolic blood pressure $(\mathrm{SBP})>$ 160 and diastolic blood pressure (DBP) > 100 were classified as being hypertensive (Ostchega et al, 2007).

\section{Treatment of Data}

The mean and standard deviations were calculated for all parameters, while independent t-test was used to compare values obtained for the male and female participants. Pearson product moment correlation was used to investigate the relationship between WHR, BMI and each of systolic and diastolic blood pressures. Significance level was set at 0.05 .

\section{RESULTS}

\section{Characteristics of Participants}

The study population consisted of 404 individuals (204 males and 200 females) with ages ranging from 15-85 years. 
These consisted of students (63\%), teachers (1.2\%), civil servants $(5.2 \%)$ and artisans $(6.25 \%)$. Their weights ranged between 30 and $116 \mathrm{~kg}$ and heights between 1.05 and $1.85 \mathrm{~m}$. Table 1 below shows the demographic characteristics and the indices of adiposity of the participants. From the table, it can be observed that male participants were significantly taller and heavier $(\mathrm{P}<0.05)$, while no significant difference existed in age between the male and female participants $(\mathrm{P}>0.05)$. Furthermore, the mean value of WHR for male participants $(0.88)$ fell below the range for the overweight and obese, while the mean value of WHR for female participants fell within the range classified as obese (McArdle et al, 2000). The mean BMI for all the participants fell within the healthy weight range (22-23 $\mathrm{kg} / \mathrm{m}^{2}$ ) (WHO, 2002). A significant difference however existed between the BMI of male and female participants $(\mathrm{p}<0.05)$.
Relationship Between Indices of Adiposity and Cardiovascular Variables of Participants

There was a significant relationship between the systolic blood pressure as well as the diastolic blood pressure, and the indices of adiposity of all the participants $(\mathrm{P}<0.05)$ (see in table 2).

\section{Comparison of Indices of Adiposity of Hypertensive and Normotensive Participants}

The participants were further classified as normotensive (SBP < 160; DBP < 100) and hypertensive (SBP > 160; DBP $>100)$. A significant difference $(\mathrm{P}<0.05)$ was observed between the WHR and BMI of hypertensive and normotensive participants. The hypertensive participants had a significantly higher WHR $(>0.9)$ as well as a significantly higher BMI $\left(>25 \mathrm{~kg} / \mathrm{m}^{2}\right)$ compared to the normotensive participants (see table 3 ).

Table 1. Demographic Characteristics and Indices of Adiposity in Participants

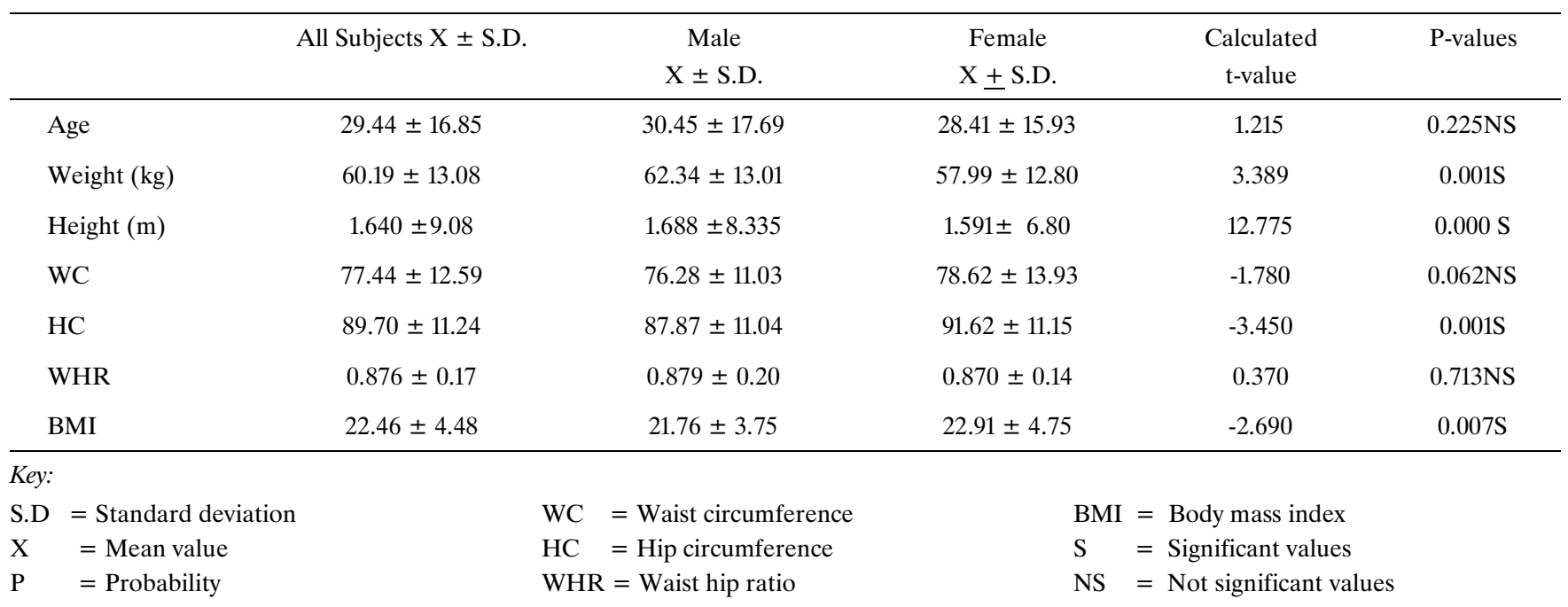

Table 2. Correlation between Indices of Adiposity and Cardiovascular Variables for all Participants

\begin{tabular}{llccc}
\hline & & WC & WHR & BMI \\
\hline SBP & $\mathrm{R}$ & 0.534 & 0.222 & 0.440 \\
& P-value & $0.000 \mathrm{~S}$ & $0.000 \mathrm{~S}$ & $0.000 \mathrm{~S}$ \\
& & & & \\
$\mathrm{DBP}$ & $\mathrm{R}$ & 0.527 & 0.209 & 0.443 \\
& P-value & $0.000 \mathrm{~S}$ & $0.000 \mathrm{~S}$ & $0.000 \mathrm{~S}$ \\
\hline
\end{tabular}

KEY:

$\mathrm{SBP}=$ systolic blood pressure

$\mathrm{DBP}=$ diastolic blood pressure

$\mathrm{WC}=$ waist circumference

$\mathrm{WHR}=$ waist hip ratio
Table 3. Comparison of Indices of Adiposity of Hypertensive and Normotensive Participants

\begin{tabular}{|c|c|c|c|c|}
\hline & $\begin{array}{c}\text { Normotensive } \\
X \pm \text { S.D. }\end{array}$ & $\begin{array}{c}\text { Hypertensive } \\
\text { X } \pm \text { S.D. }\end{array}$ & $\mathrm{t}$ value & P values \\
\hline WHR & $0.87 \pm 0.18$ & $0.97 \pm 0.11$ & -2.112 & $0.035 \mathrm{~S}$ \\
\hline BMI & $22.13 \pm 4.07$ & $30.12 \pm 6.61$ & -6.974 & $0.000 \mathrm{~S}$ \\
\hline
\end{tabular}

\section{KEY:}

$\mathrm{X} \quad=$ Mean value

S.D = Standard deviation

WHR = Waist Hip Ratio

BMI $=$ Body Mass Index

$\mathrm{S}=$ Significant Values 


\section{DISCUSSION}

In this study, the mean values of WHR for female participants $(>0.9)$ fall within the range classified as obese in women. This shows an increase in abdominal fat (Flier and Flier, 2005) for this group of participants, even though the mean value for BMI falls within the healthy weight range. This corroborates the observation by James (1996) and Welborn (2003) that WHR may prove to be a more appropriate and universal indicator of risk for an ethnically-diverse population. It has also been suggested to be a better indicator of cardiovascular risk, as it is less dependent on body size and height (James, 1996; Welborn, 2003).

Furthermore, the measurements used for obesity assessment in this study - BMI and WHR, correlated significantly with systolic and diastolic blood pressures. This result is similar to that of Canoy et al (2004), in which it was observed that waist and hip circumferences were positively related to systolic and diastolic blood pressures in male and female participants who were involved in a Norfolk cohort study. However, hip circumference was not independently correlated with blood pressure.

In addition, the result of this study showed that an increase in BMI $>25 \mathrm{~kg} / \mathrm{m}^{2}$ (Dowling and Pi-Sunyer, 1993; Nesto, 2003) and WHR > 0.9 (Flier and Flier, 2005) correlates with hypertension in both the male and female participants. This finding is in accordance with the study by Hartz et al (1984), in which it was discovered that WHR is a strong independent indicator of hypertension, particularly in men aged 40-59 years and women aged 40-69 years. However, age disparity in relation to hypertension was not taken into consideration.

\section{References}

Bray, G.A. and Gray, D.S. (1988) Obesity. Part 1- Pathogenesis. West Journal of Medicine 149: 429-41.

Cameron, A.J., Welborn, T.A. and Zimmet P.Z. (2003) Overweight and obesity in Australia: The 1999-2000 Australian Diabetes, Obesity and Lifestyle Study. Medical Journal of Australia 178, pp.427-432.

Canoy, D., Luben, R., Welch, A., Bingham, S., Wareham, N., Day, N. and Khaw, K.T. (2004) Fat distribution, body mass index and blood pressure in 22,090 men and women in the Norfolk cohort of the European prospective investigation into cancer and nutrition (EPIC-Norfolk) study. Journal of Hypertension 22(11), pp.2067-74.

Despres, J.P., Lemieux, I. and Prud'Homme, D. (2001) Treatment of obesity, need to focus on high risk abdominally obese patients. British Medical Journal 322, pp.716-720.
Dowling, H.J. and Pi-Sunyer, F.X. (1993) Race- dependent health risks of upper body obesity. Diabetes 42, pp.537-43.

Flier, J.S. and Maratos, E. (2005) Obesity. In: Kasper, D.L. and Fauci, A.S. (eds) Harrison's Principles of Internal Medicine $16^{\text {th }}$ ed. New York, McGraw-Hill, pp.423-40.

Hartz, A.J., Rupley, D.C. and Rimm, A.A. (1984) The association of girth measurements with disease in 32,856 women. American Journal of Epidemiology 119, pp.71-80.

James, W.P.T. (1996) The epidemiology of obesity: In: Chadwick, D.J. and Cardew, G. (eds) The Origin and Consequences of Obesity. (Ciba Foundation Symposium 201). Cichester, John Wiley, pp.1-16.

Lapidus, L., Bengtsson, C., Larsson, B., Pennert, K., Rybo, E. and Sjostrom, L. (1984) Distribution of adipose tissue and risk of cardiovascular disease and death: A12-year follow up of participants in the population study of women in Gothenburg, Sweden. British Medical Journal 289, pp.125761.

Lemieux, B., Prud'Homme, D., Bouchard, C., Tremblay, A. and Despres, J.P. (1996) A single threshold value of waist girth identifies normal weight and overweight subjects with excess visceral adipose tissue. American Journal of Clinical Nutrition 64, pp.683-693.

Larsson, B., Svardsudd, K. and Welin, L. (1984) Abdominal adipose tissue distribution, obesity and risk of cardiovascular disease and death: 13 year follow-up of participants in the study of men born in 1913. Br. Med. J. (Clin. Res. Ed.) 288(6428), pp.1401 - 1404.

McArdle, W.D., Katch, F.I., and Katch, V.L. (2000) Training the Anaerobic Energy Systems. Essentials of Exercise Physiology $2^{\text {nd }}$ ed. Lippincott Williams and Wilkins.

Neaton, J.D. and Wentworth, D. (1992) Serum cholesterol, blood pressure, cigarette smoking and death from coronary heart disease. Overall findings and differences by age for 316, 099 white men, multiple risk factor intervention trial research group. Archives of Internal Medicine 152, pp.56-64.

Nesto, R.W. (2003) The relation of insulin resistance syndromes to risk of cardiovascular disease. Review of Cardiovascular Medicine 4(6), pp.11-18.

Ostchega, Y., Dillon, C.F., Hughes, P., Carroll, M. and Yoon, S. (2007) Trends in hypertension-prevalence, awareness, treatment and control in older U.S. adults: Data from the National Health and Nuitrition Examination Survey 19882004. Journal of American Geriatric Society 55(7), pp.10561065.

Ohlson, L.O., Larson, B., Svarsudd, K., Welin, L., Ericksson, H. and Wilhelmson, L. (1985) The influence of body fat distribution on the incidence of diabetes mellitus, 13.5 years follow up of participants of men born in 1913. Diabetes 34(10), pp.1055-1058.

Padwal, R., Straus, S.E. and McAlister, E.A. (2001) How do cardiovascular risk affect whether we recommended therapy 
for hypertension? Evidence-based hypertension. British Medical Journal 5, pp.44.

Prineas, R.J., Folsom, A.R. and Kaye, S.A. (1993) Central adiposity and increased risk of coronary artery disease mortality in older women. Annals of Epidemiology 3, pp.3541.

Stevens, J., Cai, J. and Pamuk, E.R. (1998) The effect of age on the association between body mass index and mortality. New England Journal of Medicine 338, pp.1-7.

Visscher, T.L. and Seidell, J.C. (2001) The public health impact of obesity. Annual Review of Public Health 22, pp.355-75.

Welborn, T.A., Satvinders, D. and Bennet, S.A. (2003) Waist- hip-ratio is the dominant risk factor predicting cardiovascular death in Australia. Medical Journal of Australia 179, pp.580-585.

World Health Organization (1998) Obesity: preventing and managing the global epidemic. Report of a WHO consultation on obesity.

World Health Organization (2000) Obesity: preventing and managing the global epidemic. Geneva (WHO Technical Report Series, N0 894). http://whqlibdoc.who.int/trs/WHO TRS_894.pdf. 